УДК 51-74

\title{
МАТЕМАТИЧЕСКОЕ МОДЕЛИРОВАНИЕ УПЛОТНЕНИЯ ПРОСАДОЧНЫХ ЛЁССОВЫХ ГРУНТОВ СЕВЕРНОГО КАВКАЗА ГЛУБИННЫМИ ВЗРЫВАМИ
}

\author{
Тарасенко Елена Олеговна', \\ galail@mail.ru
}

Tарасенко Василий Сергеевич',
tarasenkovs@mail.ru

Гладков Андрей Владимирович',

gavandrew@mail.ru

Северо-Кавказский федеральный университет,
Россия, 355009, г. Ставрополь, ул. Пушкина, 1.

Актуальность. Проектирование и строительство зданий и сооружений на лёссовых просадочных грунтах на Северном Кавказе является актуальной проблемой строительства, нацеленной на обеспечение прочности и длительной эксплуатации зданий и сооружений. Актуальность проблемы связана с тем, что лёссовые грунты имеют большую мощность (до 50 м), распространены практически повсеместно (80-85 \% площади) и являются основным типом грунтовых оснований во многих городах региона. Как показал анализ литературы по данной тематике, в настоящее время не существует строгого математического описания указанного процесса. Данная работа посвящена математическому моделированию уплотнения просадочных лёссовых грунтов Северного Кавказа глубинными камуфлетными взрывами.

Цель: провести математическое моделирование уплотнения просадочных лёссовых грунтов Северного Кавказа глубинными взрывами.

Объект: просадочные лёссовые грунты Северного Кавказа.

Методы: корректное использование результатов и методов физики твёрдого тела, математики, дифференциальных уравнений, численных методов, геологии, механики грунтов и др., что способствует достижению поставленной цели.

Результаты. Анализ основных методов и способов уплотнения лёссовых просадочных грунтов Северного Кавказа показал, что метод глубинных взрывов является наиболее эффективным, мгновенным и экономически выгодным. Разработана математическая модель уплотнения лёссов глубинными взрывами на основе полуэмпирического уравнения диффузии. Она позволяет рассчитать концентрацию и плотность уплотнённого грунта в результате взрыва за заданное время при заданной температуре. Получены зависимости параметров глубинного взрыва, имеющие большое практическое значение, т. к. позволяют на основе лабораторных испытаний грунтов проектировать камуфлетные взрывы в лёссовых просадочных грунтах.

\section{Ключевые слова:}

Лёсс, просадочный грунт, уплотнение грунта, глубинный взрыв, математическое моделирование.

\section{Введение}

Лёссы занимают около 17 \% территории России $[1,2]$. Огромные территории (до 80 \% ) покрыты лёссами в Украине, Средней Азии, Казахстане, Северном Кавказе, Юге России, Восточной, Южной и Западной Сибири [3-5]. Очень часто они встречаются в Белоруссии, Поволжье, Якутии и других районах. Наибольшая территория лёссового грунта находится в Китае.

На Северном Кавказе широкое распространение имеют просадочные толщи II-го типа грунтовых условий. Следует отметить зональный характер залегания просадочных лёссовых грунтов. Глубина лёссов составляет около 50-60 м, местами до 100 м (г. Будённовск, г. Благодарный). Расчётная просадка лёссов от собственного веса достигает 2,5 м. Следует также отметить, что просадочные грунты региона имеют циклическое строение: наблюдается переслаивание горизонтов лёссовых грунтов с погребёнными почвами и лёссовидными суглинками $[2,6]$.
Лёссовый грунт имеет желтовато-палевый оттенок, представляет собой однородные пористые тонкозернистые породы. Лёссовые грунты богаты пылеватыми частицами. Наличие в лёссовых грунтах макропор даёт возможность глубокого проникновения воды в грунт, что приводит к его быстрому размоканию и неравномерным просадкам. Это можно объяснить низкой водостойкостью в связях между частицами лёссовых грунтов.

Отличительной особенностью лёссовых грунтов является деформация в виде просадки, происходящая под воздействием внешней нагрузки или под собственным весом при условии увлажнения [7, 8].

Анализ результатов исследований специалистов показал, что до 45 \% стоимости строительных работ на просадочных лёссовых грунтах направлено на предотвращение деформаций сооружений в следствии просадочности оснований.

Для устранения просадочных свойств лёссовых оснований существуют различные методы. Среди них следует отметить поверхностные и глубинные. 
Наиболее распространёнными методами уплотнения лёссовых просадочных грунтов являются следующие:

- метод механического уплотнения лёссовых грунтов тяжелыми трамбовками [5];

- уплотнение грунтовыми набивными сваями; цементация [5];

- метод предварительного замачивания лёссового массива [7];

- метод термического закрепления лёссовых грунтов [2, 9-11];

- электрохимическое закрепление грунтов [5];

- метод силикатизации лёссовых грунтов [2];

- метод глубинных взрывов [9, 12];

- уплотнение подводными взрывами [5].

Многие отечественные и зарубежные учёные модифицировали и уточняли существующие методы и способы уплотнения просадочных лёссовых грунтов, опираясь на требования практики [13-18].

В работе [17] авторы для повышения плотности грунта и ликвидации просадочности предлагают проводить динамическое воздействие на поверхности замоченного (степень влажности 0,6-0,9) лёсса путём периодических синхронных ударов трамбовки, которое осуществляется одновременно как минимум на двух участках. Энергия удара равна 5-15 атм на 1 м² площади следа уплотнения.

В.И. Осипов, С.Д. Филимонов и др. [18] предлагают устранять просадочность лёссов путём их уплотнения песчано-цементным раствором в основании зданий и сооружений. Производится нагнетание пульпы для образования трещины гидроразрыва в массиве. Далее уменьшают нагнетание пульпы, таким образом происходит остановка роста трещины. Затем производят замачивание грунта вокруг трещины. И только после этого заполняют их песчано-цементным раствором под давлением.

В.А. Кириллову и Б.Ф. Галаю [16] принадлежит авторское право на Устройство для вытрамбовывания котлованов, которое повышает плотность грунта и снижает его просадочность. При этом повышается эффективность работы вследствие увеличения энергии удара.

Метод уплотнения лёссовых грунтов глубинными взрывами в просадочной толще более 15 м был предложен и впервые применён И.М. Литвиновым в 1973 г. Недостатком метода является извлечение стальной трубы после взрыва. Существенные изменения в метод внесены Б.Ф. Галаем [15], который предложил отказаться от дорогостоящих труб.

Проведя обзор методов уплотнения просадочных грунтов, можно сделать следующие выводы:

- существует множество методов уплотнения лёссовых грунтов и их модификаций и улучшений;

- каждый из методов обладает своими достоинствами и недостатками;

- применение того или иного метода полностью зависит от условий, в которых производится уплотнение просадочного грунта;
- установлено, что метод глубинного взрыва является минимально затратным с повышенным экономическим эффектом, при этом уплотнение следует производить вдали от существующих зданий и сооружений.

\section{Разработка математической модели уплотнения просадочных лёссовых грунтов глубинными взрывами}

Рассмотрим процесс уплотнения просадочных грунтов сосредоточенными камуфлетными грунтовыми взрывами. Сущность камуфлетирования заключается в образовании уширенной полости путём взрывания заряда взрывчатого вещества (BВ), заложенного на требуемой глубине. При этом нижняя часть просадочной толщи уплотняется собственным весом вышележащего грунта под действием силы тяжести. После глубинных взрывов производят уплотнение верхнего «буферного» слоя поверхностными методами уплотнения грунтов.

Построим математическую модель диффузии газа в просадочных грунтах в результате сосредоточенного глубинного взрыва на основе полуэмпирического уравнения диффузии, которая даст возможность оценить концентрацию и плотность уплотненного грунта.

Процесс диффузии атомов газа при глубинном грунтовом взрыве от мгновенного точечного источника (сосредоточенный заряд) предлагается описать на основе начально-граничной задачи [19]:

$$
\begin{gathered}
\frac{\partial q}{\partial t}+\sum_{i=1}^{3} u_{i} \frac{\partial q}{\partial x_{i}}+\alpha q+\sum_{i=1}^{3} \sum_{j=1}^{3} \frac{\partial}{\partial x_{i}} K_{i j} \frac{\partial q}{\partial x_{j}}=0, \\
q\left(t_{0}, x_{1}, x_{2}, x_{3}\right)=Q \delta\left(x_{1}-x_{1}^{0}\right) \delta\left(x_{2}-x_{2}^{0}\right) \delta\left(x_{3}-x_{3}^{0}\right), \\
t \in\left[t_{0}, T\right], \\
\left.K_{33} \frac{\partial q}{\partial x_{3}}\right|_{x_{3}=x_{3}^{0}}=0, t>t_{0}
\end{gathered}
$$

в случае, когда атомы газа отражаются от окружающего его грунта (происходит выброс) на глубине $x_{3}{ }^{0}$ (глубина заложения заряда); начально-граничной задачи (1), (2)

$$
\left.q\left(t, x_{1}, x_{2}, x_{3}\right)\right|_{x_{3}=x_{3}^{0}}=0, t>t_{0},
$$

в случае, когда газ полностью поглощается окружающим его грунтом; и краевой задачи (1), (2)

$$
\left.\left\{K_{33} \frac{\partial q}{\partial x_{3}}+\varpi q\right\}\right|_{x_{3}=x_{3}^{0}}=\left.\left\{v_{s} q\right\}\right|_{x_{3}=x_{3}^{0}}
$$

в случае, когда газ частично отражается и частично поглощается окружающим его грунтом. Здесь $Q$ - мощность заряда взрывчатого вещества (т. е. количество газа, выброшенного зарядом в момент времени $t_{0}$ в точке $\left.\left(x_{0}, y_{0}, z_{0}\right)\right) ; \delta$ - дельтафункция; $\varpi-$ скорость распространения газа в камуфлетной области под действием гравитации; $v_{s}-$ результирующая скорость осаждения или прони- 
кновения атомов газа в окружающий его грунт. Равенство (5) показывает, что поток газа на окружающий его грунт складывается из двух слагаемых: потока сил диффузии $\left.\left\{K_{33} \frac{\partial q}{\partial x_{3}}\right\}\right|_{x_{3}=x_{3}^{0}}$ и грави-
тации $\left.\{\varpi q\}\right|_{x_{3}=x^{0}}$.

На рис. 1 показано схематическое изображение глубинного грунтового взрыва, когда источник газа (заряд взрывчатого вещества) является сосредоточенным и задан функцией источника $f$. Проникновение частиц газа в окружающий его грунт происходит под действием энергии взрыва.

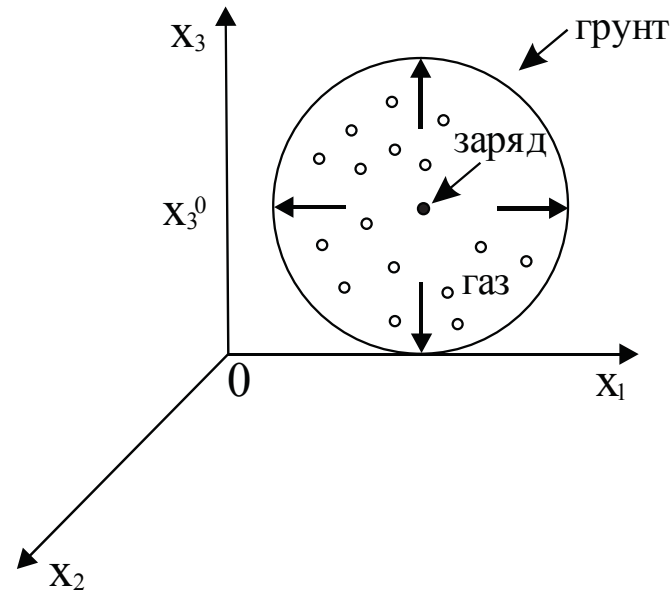

Pис. 1. Схематическое изображение глубинного грунтового взрыва

Fig. 1. Schematic representation of a deep underground explosion

Пусть вектор $\vec{u}=\left(u_{1}, u_{2}, u_{3}\right)$ является постоянным и направлен вдоль горизонтальной оси $O x_{1}$ (т. е. $u_{2}=u_{3}=0$ ), элементы матрицы $K$ имеют вид:

$$
K_{i j}=\left\{\begin{array}{l}
\sigma_{i}^{2}, i=j, \sigma_{i}=\text { const }>0 ; \\
0, i \neq j, i, j=1,2,3
\end{array}\right.
$$

$\alpha=0$ (т. е. газ не вступает в реакцию с окружающей средой и не разлагается).

Аналитическое решение задач (1)-(3) и (1), (2), (4) можно записать в виде [20]:

$$
\begin{gathered}
\quad q\left(t, x_{1}, x_{2}, x_{3}\right)=\frac{Q}{\left(4 \pi\left(t-t_{0}\right)\right)^{3 / 2} \sigma_{1} \sigma_{2} \sigma_{3}} \times \\
\times \exp \left\{-\frac{\left(x_{1}-u_{1}\left(t-t_{0}\right)\right)^{2}}{4 \sigma_{1}^{2}\left(t-t_{0}\right)}-\frac{x_{2}{ }^{2}}{4 \sigma_{2}^{2}\left(t-t_{0}\right)}\right\} \times \\
\times\left[\exp \left\{-\frac{\left(x_{3}-H\right)^{2}}{4 \sigma_{3}^{2}\left(t-t_{0}\right)}\right\}+\exp \left\{-\frac{\left(x_{3}+H\right)^{2}}{4 \sigma_{3}^{2}\left(t-t_{0}\right)}\right\}\right] ; \\
\\
\quad q\left(t, x_{1}, x_{2}, x_{3}\right)=\frac{Q}{\left(4 \pi\left(t-t_{0}\right)\right)^{3 / 2} \sigma_{1} \sigma_{2} \sigma_{3}} \times \\
\times \exp \left\{-\frac{() x_{1}-u_{1}\left(t-t_{0}\right)^{2}}{4 \sigma_{1}^{2}\left(t-t_{0}\right)}-\frac{x_{2}{ }^{2}}{4 \sigma_{2}^{2}\left(t-t_{0}\right)}\right\} \times \\
\times\left[\exp \left\{-\frac{\left(x_{3}-H\right)^{2}}{4 \sigma_{1}^{2}\left(t-t_{0}\right)}\right\}-\exp \left\{-\frac{\left(x_{3}+H\right)^{2}}{4 \sigma_{1}^{2}\left(t-t_{0}\right)}\right\}\right],
\end{gathered}
$$

где заряд $\mathrm{BB}$ с мощностью $Q=$ const $>0$ действует в момент времени $t_{0}$ в точке $(0,0, H)$.

Согласно Руководству по проектированию оснований зданий и сооружений [21], прочность структурных связей лёссовых грунтов можно характеризовать удельным сопротивлением пенетрации $q_{\text {п }}$. По сопротивлению пенетрации грунты классифицируют по прочности и делят на очень прочные, прочные, средней прочности и слабые грунты.

Естественные маловлажные лёссы имеют удельное сопротивление пенетрации $q_{\text {п }}>2$ кгс $/ \mathrm{cm}^{2}$. Их относят к очень прочным грунтам. Перевести их в разряд среднепрочных $\left(q_{\text {п }}=1-2 \mathrm{\kappa гc} / \mathrm{cm}^{2}\right)$ или слабых $\left(q_{\pi}=0,5-1 \kappa г c / \mathrm{cm}^{2}\right)$ грунтов удаётся путём их замачивания. Прочность водонасыщенных лёссовых грунтов увеличивается после разрушения их структурных связей. С этой целью прибегают к уплотнению грунтов глубинными взрывами.

Заметим, что выбор метода нахождения корней дифференциальных уравнений с заданными начальным и граничными условиями (1)-(3) и (1), (2), (4) не является принципиальным. Нами был выбран итерационный метод решения поставленных задач. На рис. 2 представлена блок-схема общего алгоритма решения задачи переноса частиц грунта.

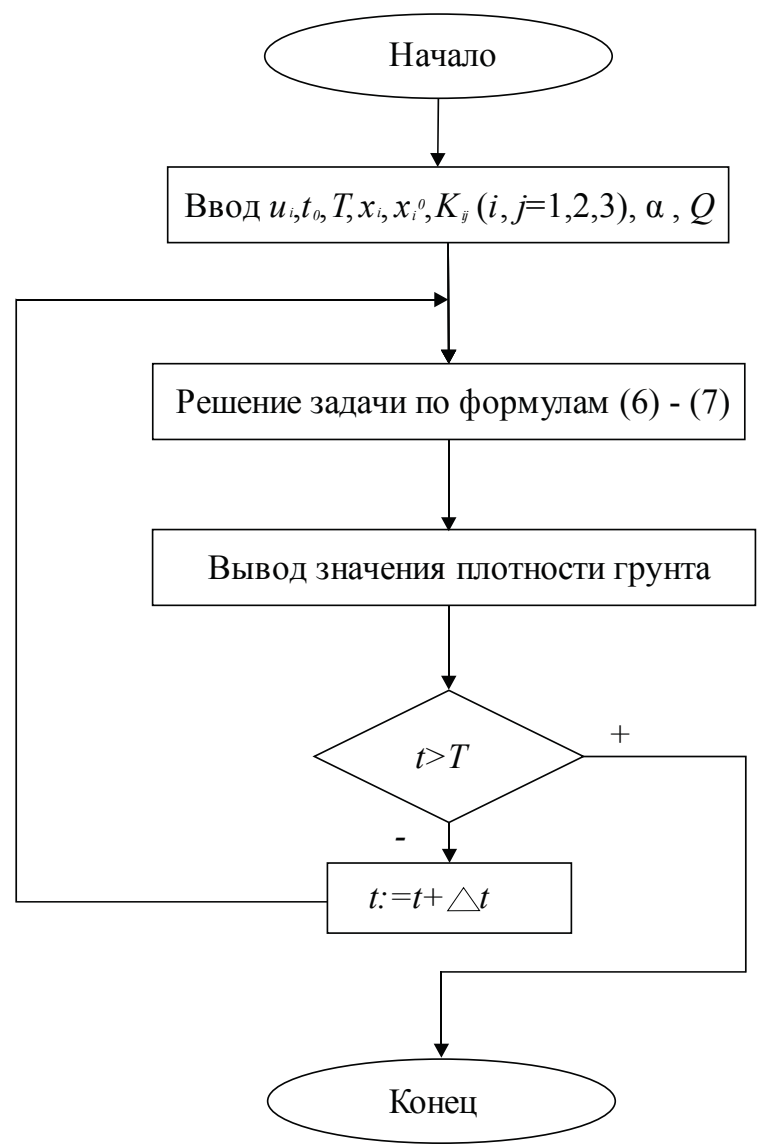

Рис.2. Главный алгоритм расчета средних значений плотности грунта

Fig. 2. Main algorithm for calculating the average values of soil density 
Предложенная математическая модель позволяет описать диффузионное проникновение атомов газа в окружающий его грунт. С её помощью можно рассчитать концентрацию (6), (7) и плотность уплотненного грунта в результате глубинного взрыва за заданное время при заданной температуре.

\section{Вычислительный эксперимент проектирования} камуфлетных взрывов в просадочных грунтах

В зависимости от вида грунтов, требуемого диаметра камуфлетной полости, глубины заложения $\mathrm{BB}$, а также условий строительства образование камуфлета может производиться одним или двумя взрывами, применением кольца зарядов, группированием зарядов по периметру скважины и др. [22].

Для образования камуфлетов заданных размеров вес заряда ВВ можно определить по формуле [22]:

$$
C=K_{\Pi} Д^{3},
$$

где $K_{\text {П }}$ - коэффициент сопротивления грунта отжатию взрывом, кг $/ \mathrm{cm}^{3}$.

На рис. 3 представлена зависимость коэффициента сопротивления суглинка отжатию взрывом от его консистенции. Расчёты проводились для массы заряда $C=1$ кг по формуле (8). Анализ зависимости показал, что для твёрдого суглинка значение коэффициента сопротивления грунта отжатию взрывом составляет 2,6 кг/ $\mathrm{cm}^{3}$, а для текучепластичного суглинка $-0,9 \mathrm{\kappa г} / \mathrm{cm}^{3}$.

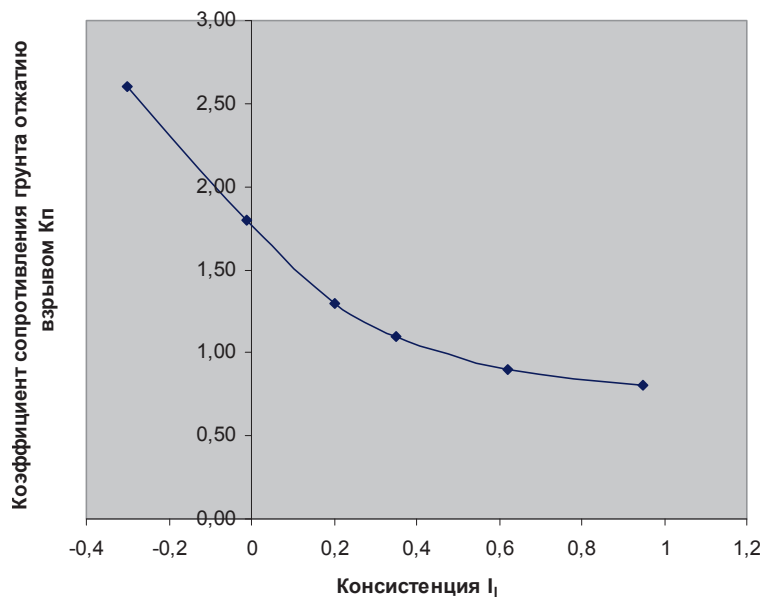

Pис.3. Зависимость коэффициента сопротивления грунта отжатию взрывом от его консистениии

Fig. 3. Dependence of soil resistance coefficient to release by explosion on its consistency

Из (1) определим диаметр камуфлетной полости Д, м:

$$
\text { Д }=\sqrt[3]{\frac{C}{K_{\Pi}}} .
$$

Консистенция глинистых грунтов является надёжным параметром определения диаметра камуфлетной полости (9) в грунтах. На рис. 4 представлена зависимость диаметра камуфлетной полости от консистенции суглинка. Расчёты проводились для значения $C=1$ кг (8). Как видно из рис. 4 , с увеличением влажности и консистенции суглинка наблюдается расширение диаметра камуфлетной полости. Для твёрдого суглинка диаметр камуфлетной полости составляет 0,58 м, а для суглинка текучепластичного - 1,25 м. Увеличение диаметра камуфлетной полости в два раза в текучепластичном суглинке объясняется резким снижением прочности структурных связей при замачивании дисперсных грунтов.

Из рис. 4 видно, что для грунтов в твёрдом и полутвёрдом состоянии (при показателе консистенции $\mathrm{I}_{\mathrm{L}}$ до 0,2) график имеет пологий наклон, затем в пластичном состоянии увеличение диаметра происходит более интенсивно, а в текучем состоянии график снова приобретает пологий характер.

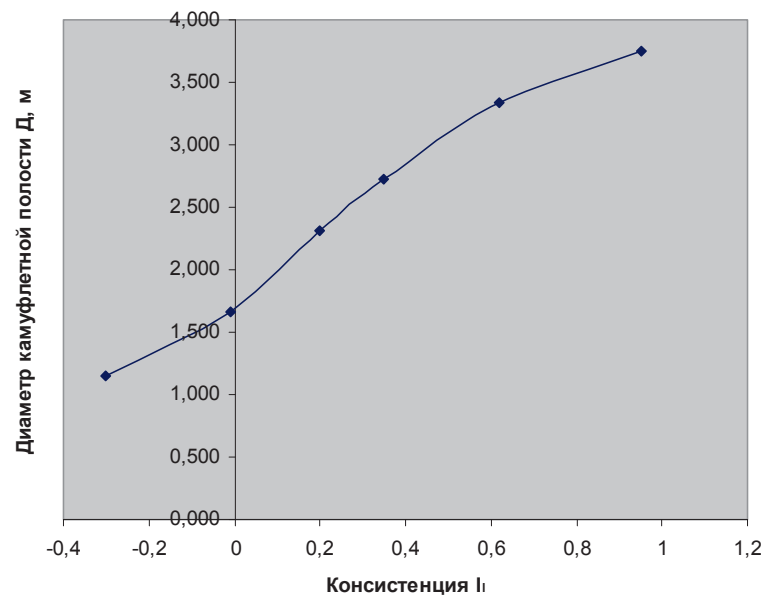

Рис. 4. Зависилость диаметра калуфлетной полости от консистениии грунта

Fig. 4. Dependence of camouflage cavity diameter on soil consistency

На рис. 5 представлена зависимость диаметра камуфлетной полости от модуля деформации для суглинков при различных значениях коэффициента пористости, характеризующего плотность грунта.

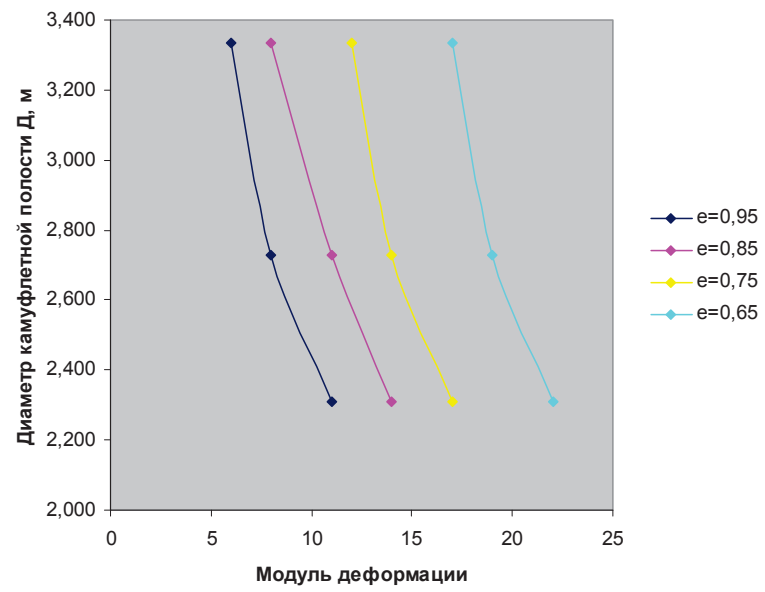

Рис. 5. Зависилость диалетра камуфлетной полости от модуля дефорлации для различных значений коэффициента пористости е

Fig. 5. Dependence of camouflage cavity diameter on deformation modulus for various values of the porosity coefficient $e$ 
Из рис. 5 следует, что в более плотных и более прочных (слабо сжимаемых) грунтах диаметр камуфлетных полостей снижается примерно в 1,5 раза по сравнению с обводненными, сильно деформируемыми суглинками.

Полученные зависимости имеют большое практическое значение, т. к. позволяют на основе лабораторных испытаний глинистых грунтов проектировать камуфлетные взрывы в просадочных и слабых грунтах.

Поставленная нами задача решена для сосредоточенных камуфлетных зарядов. Задачей дальнейших исследований является изучение зависимостей линейных зарядов, которые используются при устройстве буронабивных грунтовых и бетонных свай в слабых, просадочных и других структурно-неустойчивых грунтах.

\section{Заключение}

В ходе анализа основных методов и способов уплотнения просадочных грунтов Северного Кав-

\section{СПИСОК ЛИТЕРАТУРЫ}

1. Лёссовые породы СССР. Т. 1. Инженерно-геологические особенности и проблемы рационального использования / под ред. Е.М. Сергеева, А.К. Ларионова, Н.Н. Комиссаровой. - М.: Недра, 1986. - 273 с.

2. Лёссовые породы СССР. Т. 2. Региональные особенности / под ред. Е.М. Сергеева, В.С. Быковой, Н.Н. Комиссаровой. - М.: Недра, 1986. - 276 c.

3. Лёссовые грунты Северного Кавказа и Крыма (сравнительный анализ) / Б.Ф. Галай, В.В. Сербин, В.С. Плахтюкова, О.Б. Галай // Наука. Инновации. Технологии. - 2017. - № 2. C. $97-108$.

4. Галай Б.Ф. Уплотнение просадочных грунтов глубинными взрывами. - Ставрополь: Изд-во Северо-Кавказского Федерального университета, 2018. - 240 c.

5. Пантюшина Е.В. Лёссовые грунты и инженерные методы устранения их просадочных свойств // Ползуновский вестник. - 2011. - № 1. - С. 127-130.

6. Критические замечания к положениям нормативных документов по оценке просадочности лёссовых грунтов по их физическим характеристикам / Б.Ф. Галай, В.В. Сербин, В.С. Плахтюкова, О.Б. Галай // Инженерные изыскания. - 2016. № 14. - C. 18-22.

7. Tsukamoto Y., Ishihara K. Analysis on settlement of soil deposits following liquefaction during earthquakes // Soils and Foundation. - 2010. - № 50 (3). - P. 399-441.

8. Consolidation of organic subsoil's by applying underground explosions for formations of vertical sands drains and generating dynamic overloading / E. Dembicki, N. Kisielowa, R. Bona, R. Imiolek, A. Michowski, I. Semrau // Proc. 9 Int. Harbour Congress, Antwerp. - 1988. - P. 5.165-5.170.

9. Ishihara K. New challenges in geotechnique for ground hazards due to intensely strong earthquake shaking / Geotechnical, Geological and Earthquake Engineering. - 2009. - № 11. P. 91-114

10. Nishiama H. Martensitic theory transformations. - New-York: Academic, 1981. $-315 \mathrm{p}$

11. Ivanov P.L. Compaction of Cohesionless soils by explosives // Proc. of the VI International Conference on soil mechanics and foundation engineering. - Montreal, 1966. - V. 3. - P. 352-354. каза установлено, что наиболее эффективным, мгновенным и экономически выгодным является метод глубинных взрывов.

Построена математическая модель глубинного сосредоточенного грунтового взрыва на основе полуэмпирического уравнения диффузии, позволяющая рассчитать концентрацию и плотность уплотнённого грунта в результате глубинного взрыва за заданное время при заданной температуре и описывающая проникновение атомов газа в окружающий его грунт.

Проведённый вычислительный эксперимент проектирования взрывов позволил получить зависимости, которые имеют большое практическое значение, т. к. позволяют на основе лабораторных испытаний грунтов проектировать камуфлетные взрывы в просадочных и слабых грунтах.

Авторы выражают признательность доктору геологоминералогических наук, профессору, профессору кафедры строительства Северо-Кавказского Федерального университета Борису Фёдоровичу Галаю за оказанную помощь при проведении данного научного исследования.

12. Hall C.E. Compacting a dam foundation by blasting // Journal of Soil Mechanics and Foundation Division. - 1962. - V. 88. № SM3. - P. 31-51.

13. Dynamic consolidation of organic subsoil's by use of hidden underground explosions / E. Dembicki, N. Kisielowa, R. Bona, R. Imiolek, A. Michowski, I. Semrau // Proc. of the II Baltic Conf. S.M.F.E. - Tallinn, 1988. - P. 273-277.

14. Liman A.K. Compaction of Cohesionless foundation soils by explosives // Civil Engineering. - 1940. - V. 10. - Iss. 4. - P. 9-15.

15. Способ возведения буронабивной сваи: пат. Рос. Федерация, № 2135691, заявл. 10.11.1998; опубл. 27.08.1999. - 8 с.

16. Кириллов В.А., Галай Б.Ф. Устройство для вытрамбовывания котлованов. Авторское свидетельство СССР № 1214841, 28.02.1986, Бюл. № 8.

17. Крутов В.И., Рабинович И.Г. Способ уплотнения массива лёссового просадочного грунта. Авторское свидетельство Союза Советских Социалистических Республик, № 1308703, 07.05.1987, Бюл. № 17.

18. Способ уплотнения лёссовых грунтов в основании зданий и сооружений: пат. Рос. Федерация, № 2015247, заявл. 27.12.1991; опубл. 30.06.1994. - 6 с.

19. Тарасенко Е.О., Гладков А.В., Маликова Н.В. Разрешимость краевых задач, описывающих диффузию атомов пленки в подстилающей поверхности при образовании тонкопленочных структур // Известия Томского политехнического университета. Инжиниринг георесурсов. - 2016. - Т. 327. - № 2. C. $125-132$

20. Математическое моделирование сосредоточенного глубинного взрыва на основе уравнения диффузии / Е.0. Тарасенко, А.В. Гладков, П.К. Корнеев, В.С. Тарасенко // Естественные науки - основа настоящего и фундамент для будущего: Материалы VI-й ежегодной научно-практической конференции СевероКавказского федерального университета «Университетская наука - региону». - Ставрополь: Изд-во Северо-Кавказского Федерального университета, 2018. - 583 с.

21. Руководство по проектированию оснований зданий и сооружений. - М.: Стройиздат, 1977. - 376 с.

22. Указания по устройству буронабивных свай в связных грунтах. - Алма-Ата, Караганда, 1975. - 52 с. 


\section{Информация об авторах}

Tapaceнко E.O., кандидат физико-математических наук, доцент кафедры прикладной математики и математического моделирования Северо-Кавказского федерального университета.

Tарасенко B.C., студент магистратуры направления подготовки «Математика и компьютерные науки», ведущий специалист по эксплуатационно-техническому обслуживанию сектора эксплуатации информационного технической инфраструктуры учебных корпусов эксплуатационно-технического отдела средств вычислительной техники Управления информатизации Северо-Кавказского федерального университета.

Гладков A.B., старший преподаватель кафедры прикладной математики и математического моделирования Северо-Кавказского федерального университета. 
UDC 51-74

\title{
MATHEMATICAL MODELING OF CONSOLIDATION OF SUBSIDENCE LOESS SOILS OF THE NORTH CAUCASUS BY DEEP EXPLOSIONS
}

\author{
Elena O. Tarasenko',
}

galail@mail.ru

Vasily S. Tarasenko',

tarasenkovs@mail.ru

\author{
Andrey V. Gladkov', \\ gavandrew@mail.ru \\ North-Caucasian Federal University,
1, Pushkin street, Stavropol, 355009, Russia.
}

Relevance. Design and construction of buildings and structures on loess subsidence soils in the North Caucasus is a relevant problem of construction aimed at ensuring the strength and long-term operation of buildings and structures. The relevance of the problem is related to the fact that loess soils have large capacity (up to $50 \mathrm{~m}$ ), are distributed almost everywhere $(80-85 \%$ of the area) and are the main type of soil bases in many cities of the region. As it is shown by the analysis of the literature on this topic, currently there is no strict mathematical description of this process. This work is devoted to mathematical modeling of compaction of subsidence loess soils of the North Caucasus by deep camouflage explosions.

The aim of the research is to carry out a mathematical modeling of compaction of subsiding loess soils of the North Caucasus by deep explosions.

Object: subsidence loess soils of the North Caucasus.

Methods: correct use of results and methods of solid body physics, mathematics, differential equations, numerical methods, geology, mechanics of soil, etc. that promotes achievement of a goal.

Results. The analysis of the main methods and techniques of compaction of loess subsiding soils of the North Caucasus showed that the deep explosions method is the most effective, instantaneous and cost-effective. A mathematical model for compaction of loess by deep explosions based on the semi-empirical diffusion equation was developed. It allows you to calculate the concentration and density of compacted soil as a result of explosion for a specified time at a given temperature. The dependences of the parameters of a deep explosion, which are of great practical importance, are obtained, since they allow designing camouflet explosions in loess subsided soils on the basis of laboratory tests of soils.

\section{Key words:}

Loess, subsurface soil, soil compaction, deep explosion, mathematical modeling.

The authors express their gratitude to Boris F. Galay, Dr. Sc., professor, professor of the Department of construction of the North-Caucasus Federal University, for assistance in this research.

\section{REFERENCES}

1. Lessove porody SSSR. T. 1. Inzhenerno-geologicheskie osobennosti i problemy ratsionalnogo ispolzovaniya [Loess rocks of the USSR. Vol. 1. Engineering-geological features and problems of rational use]. Eds. E.M. Sergeev, A.K. Larionov, N.N. Komissarova. Moscow, Nedra Publ., 1986. 273 p.

2. Lessovye porody SSSR. T. 2. Regionalnye osobennosti [Loess rocks of the USSR. Vol. 2. Regional features]. Eds. E.M. Sergeev, V.S. Bykova, N.N. Komissarova. Moscow, Nedra Publ., 1986. $276 \mathrm{p}$.

3. Galai B.F., Serbin V.V., Platonova V.S., Galai O.B. Loess soils of the North Caucasus and Crimea (comparative analysis). Science. Innovations. Technologies, 2017, no. 2, pp. 97-108. In Rus.

4. Galai B.F. Uplotnenie prosadochnykh gruntov glubinnymi vzryva$m i$ [Compaction of collapsible soils by the deep explosions]. Stavropol, North Caucasus Federal University Publ. house, 2018. $240 \mathrm{p}$.

5. Pantyushina E.V. Loess soils and engineering methods for eliminating their drawdown properties. Polzunousky Vestnik, 2011, no. 1. pp. 127-130. In Rus.

6. Galai B.F., Serbin V.V., Platonova V.S., Galai O.B. Criticisms to the provisions of the regulations on the assessment of subsidence of loess soils according to their physical characteristics. Engineering surveys, 2016, no. 14, pp. 18-22. In Rus.
7. Tsukamoto Y., Ishihara K. Analysis on settlement of soil deposits following liquefaction during earthquakes. Soils and Foundation, 2010, no. 50 (3), pp. 399-441.

8. Dembicki E., Kisielowa N., Bona R., Imiolek R., Michowski A., Semrau I. Consolidation of Organic Subsoil's by Applying Underground Explosions for Formations of Vertical Sands Drains and Generating Dynamic Overloading. Proc. 9 Int. Harbour Congress, Antwerp, 1988. pp. 5.165-5.170.

9. Ishihara K. New challenges in Geotechnique for ground hazards due to intensely strong earthquake shaking. Geotechnical, Geological and Earthquake Engineering, 2009, no. 11, pp. 91-114.

10. Nishiama H. Martensitic Theory Transformations. Academic, New-York, 1981. $315 \mathrm{p}$

11. Ivanov P.L. Compaction of Cohesionless Soils by Explosives. Proc. of the VI International Conference on Soil Mechanics and Foundation Engineering. Montreal, 1966. Vol. 3, pp. 352-354.

12. Hall C.E. Compacting a dam foundation by blasting. Journal of Soil Mechanics and Foundation Division, 1962, vol. 88, no. SM3, pp. 31-51.

13. Dembicki E., Kisielowa N., Bona R., Imiolek R., Michowski A., Semrau I. Dynamic Consolidation of Organic Subsoil's by Use of Hidden Underground Explosions. Proc. of the II Baltic Conf. S.M.F.E. Tallinn, 1988. pp. 273-277.

14. Liman A.K. Compaction of Cohecionless Foundation Soils by Explosives. Civil Engineering, 1940, vol. 10, Iss. 4, pp. 9-15. 
15. Galai B.F. Sposob vozvedeniya buronabivnoy svay [Method of construction of bored piles]. Patent RF, no. 2135691, 1999.

16. Kirillov V.A., Galai B.F. Ustroystvo dlya vytrambovyvaniya kotlovanov [The device for indentation of the pits]. Copyright certificate of the Union of Soviet Socialist Republics, no. 1214841, 1986.

17. Krutov V.I., Rabinovich I.G. Sposob uplotneniya massiva lyossovogo prosadochnogo grunta [Method of sealing an array loess subsidence of the soil]. Author's certificate of the Union of Soviet Socialist Republics, no. 1308703, 1987.

18. Osipov V.I., Filimonov S.D., Melnikov B.N., Kail E.V. Sposob uplotneniya lyossovykh gruntov $v$ osnovanii zdaniy i sooruzheniy [Method of compaction of loess soils at the base of buildings and structures]. Patent RF, no. 2015247, 1994.

19. Tarasenko E.O., Gladkov A.V., Malikov N.B. Solvability of boundary value problems describing the diffusion of atoms of the film to the underlying surface during the formation of thin-film structures. Bulletin of the Tomsk Polytechnic University. Geo Assets Engineering, 2016, vol. 327, no. 2, pp. 125-132. In Rus.

20. Tarasenko E.O., Gladkov A.V., Korneev P.K., Tarasenko V.S. Matematicheskoe modelirovanie sosredotochennogo glubinnogo vzryva na osnove uravneniya diffuzii [Mathematical modeling of concentrated deep explosion on the basis of the diffusion equation]. Estestvennye nauki - osnova nastoyashchego $i$ fundament dlya budushchego. Materialy VI ezhegodnoj nauchno-prakticheskoj konferencii Severo-Kavkazskogo federalnogo universiteta «Universitetskaya nauka - regionu». [Natural Sciences - the basis of the present and the Foundation for the future: Materials of the VI annual scientific-practical conference of the North Caucasus Federal University «University of science-the region»]. Stavropol, North-Caucasian Federal University Publ., 2018. pp. 66-68.

21. Rukovodstvo po proektirovaniyu osnovaniyu zdaniy i sooruzheniy [Guidelines for the design of foundations of buildings and structures]. Moscow: Stroyizdat, 1977. 376 p.

22. Ukazaniya po ustroystvu buronabivnykh svay $v$ svyaznykh gruntakh [Instructions on the device of bored piles in cohesive soils]. Alma-ATA, Karaganda, 1975. 52 p.

Received: 18 February 2019.

\section{Information about the authors}

Elena O. Tarasenko, Cand. Sc., assistant professor, North-Caucasian Federal University.

Vasily S. Tarasenko, graduate student, leading specialist in maintenance sector operation of information infrastructure of educational buildings maintenance, North-Caucasian Federal University.

Andrey V. Gladkov, senior teacher, North-Caucasian Federal University. 